\title{
Similar 10-year survival in breast cancer patients of Lithuania and Poland with common BRCA1 founder mutations
}

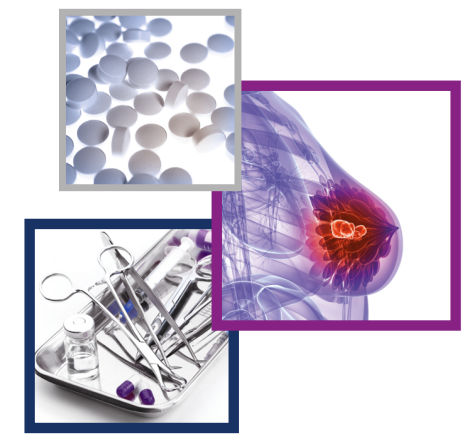

\author{
Pavel Elsakov*,1, Valerij Ostapenko², Audrone Luksyte ${ }^{3}$ \& Giedre Smailyte ${ }^{4}$ \\ ${ }^{1}$ Diagnostic Center, Therapy Consultation Department, Public Institution Central Outpatient Clinic, Vilnius, Lithuania \\ ${ }^{2}$ Breast Surgery \& Oncology Department, National Cancer Institute, Vilnius, Lithuania \\ ${ }^{3}$ Consulting Polyclinic, National Cancer Institute, Vilnius, Lithuania \\ ${ }^{4}$ Cancer Epidemiology Laboratory, National Cancer Institute, Vilnius, Lithuania \\ *Author for correspondence: pavel.elsakov@gmail.com
}

\begin{abstract}
'In each country, the long-term and the 5-year survival rates are statistically similar among women with breast cancer and between BRCA1 founder mutation carriers and noncarriers, and are not dependent on the different contributions of founder mutations."
\end{abstract}

First draft submitted: 12 October 2018; Accepted for publication: 23 October 2018; Published online: 22 May 2019

\section{To the Editor}

In 2017, we published results of a study that suggested that the 5-year survival rates for breast cancer patients in the Lithuanian population were not dependent on their BRCA1 founder mutation carrier status or family history, when identical management and treatment were received [1]. These results were comparable with a study in Poland where the 10-year overall survival for patients with early onset breast cancer was similar regardless of BRCA1 mutation carrier status [2]. Three BRCA1 mutations, 4153delA, 5382insC and C61G, are founder mutations in the Polish and Lithuanian populations for breast cancer, in both hereditary breast cancer syndrome, and in unselected breast cancer cases [3,4]. The collaborative study also suggested that the 4153 delA mutation is prevalent in Lithuanian BRCA1-associated breast cancer patients [4]. These three frequent founder mutations in the BRCA1 gene have been recently described in the neighboring populations of both Balts (Latvia) [5] and Slavs (Belarus and Russia) [6-8].

Breast cancers with such a common BRCA1 founder mutation association can be biologically identical in terms of response to classical standard treatment regimens commonly used for breast cancer patients in both these countries. Therefore it is reasonable to assume that there will be similar prognoses and long-term survival in BRCA1-associated breast cancer patients in Lithuania and Poland.

The aim of this new study is to estimate in Lithuania the 10-year survival of breast cancer patients with 4153delA, a common (but with differing prevalence) BRCA1 founder mutation, and compare this with the 10-year survival rates in Poland. The study focused on the same cohort as in previous study [1]; 263 breast cancer patients (47 familial cancer patients selected by strong hereditary breast cancer criteria and 216 consecutive patients unselected for age or family history) diagnosed in stage (Tumor, Node, Metastasis [TNM]) I-III and treated at the Vilnius Oncology Institute (Lithuania). In Lithuania, the studied breast cancer patients had been undergoing treatment during since the initial diagnosis and the identification of their carrier status for BRCA1 founder mutations 4153delA, 5382insC and C61G. The treatment of all patients during the period was as per national protocols for treatment of breast cancer cases independent of mutation status. The patient characteristics are shown in Table 1 .

Survival curves were generated using the Kaplan-Meier method and were compared using the log-rank test. The vital status of the study group was assessed as of 28 February 2017, and $\mathrm{p}<0.05$ indicated a significant statistical difference. Cox's proportional hazards regression models were used to estimate the adjusted hazard ratio (HR) and 95\% confidence interval (CI) and to estimate the effect of family history and mutation status, while adjusting for the possible confounding effects of relevant clinical variables. All statistical analyses were performed using Stata Statistical Software version 11.0. (Stata Corp. 2009. Stata Statistical Software: Release 11.0., TX, USA).

The results of our study suggested that the 10-year survival rate among breast cancer patients with BRCA1 founder mutation is similar to those without a BRCA1 mutation ( $p=0.7138$; see Figure 1 ). The adjusted HR

Future $\because$ Medicine 
Table 1. Characteristics and results of univariable and multivariable analyses of breast cancer patients.

\begin{tabular}{|c|c|c|c|c|}
\hline \multirow[t]{2}{*}{ Characteristics } & \multirow{2}{*}{ Cancers } & \multirow[t]{2}{*}{ Deaths } & \multicolumn{2}{|c|}{ Hazard ratios ( $95 \%$ confidence interval) } \\
\hline & & & Unadjusted & Adjusted \\
\hline \multicolumn{5}{|l|}{ Mutation: } \\
\hline$-\mathrm{No}$ & 240 & 71 & Ref. & Ref. \\
\hline- Yes & 23 & 11 & $1.14(0.58-2.24)$ & $1.04(0.49-2.23)$ \\
\hline \multicolumn{5}{|l|}{ Familial cancer: } \\
\hline - Yes & 47 & 25 & Ref. & Ref. \\
\hline- No & 216 & 57 & $0.86(0.51-1.46)$ & $0.73(0.41-1.28)$ \\
\hline \multicolumn{5}{|l|}{ Age group: } \\
\hline$-\leq 52$ & 126 & 27 & Ref. & Ref. \\
\hline$->52$ & 137 & 55 & $2.74 *(1.70-4.41)$ & $3.17 *(1.94-5.19)$ \\
\hline Stage I & 90 & 13 & Ref. & Ref. \\
\hline Stage II & 123 & 42 & $2.44 *(1.30-4.56)$ & $2.78 *(1.46-5.26)$ \\
\hline Stage III & 50 & 27 & $5.47 *(2.82-10.62)$ & $6.02 *(3.09-11.75)$ \\
\hline
\end{tabular}

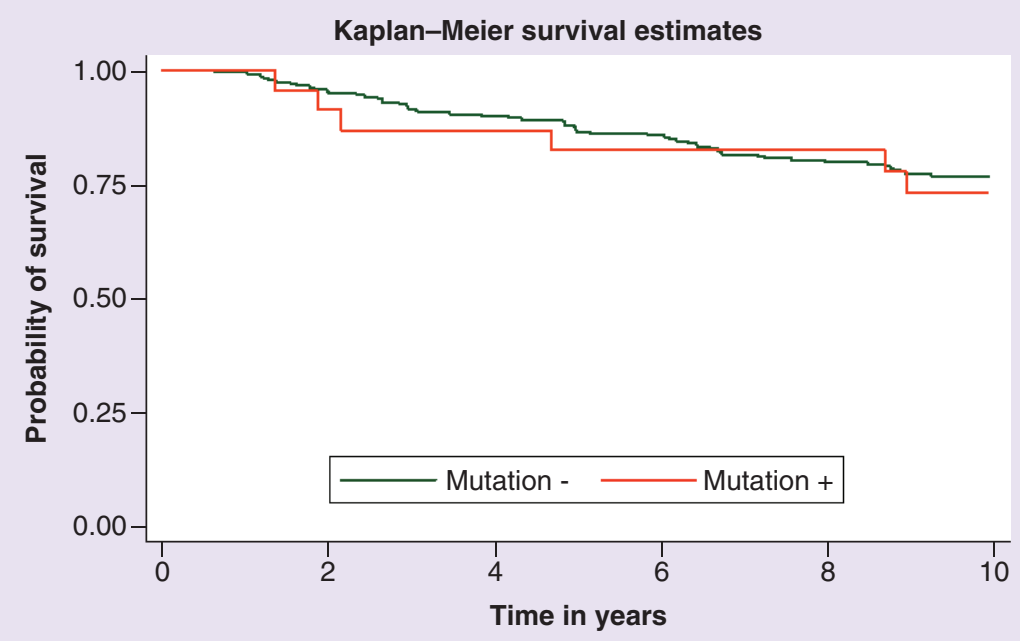

Figure 1. The 10-year survival of breast cancer patients by BRCA1 with negative and positive founder mutation.

associated with carrying a BRCA1 founder mutation was 1.04 (95\% CI: 0.4-2.23; p > 0.05). The results of univariable and multivariable analysis of breast cancer patients is shown in Table 1.

These results of our study are similar to results of the Poland study, where the 10-year survival rate for BRCA1 mutation carriers was $80.9 \%$ (95\% CI: 75.4-86.4\%); for no carriers, it was 82.2\% (95\% CI: $80.5-83.7 \%$, not significantly different). The adjusted HR associated with carrying a BRCA1 mutation was 1.81 (95\% CI: 1.262.61) [3]. In each country, the long-term and the 5-year survival rates are statistically similar among women with breast cancer and between BRCA1 founder mutation carriers and noncarriers, and are not dependent on the different contributions of founder mutations.

Similarly, evidence from a cohort study conducted in Canada, the USA and Australia showed that the risks of distant recurrence and death did not differ significantly between BRCA1 mutation carriers and those with sporadic disease for long survival period (12 years) in univariable and multivariable analyses (including adjusted for estrogen receptor and progesterone receptor status) [9].

The majority of BRCA1 breast cancers are invasive ductal carcinoma that are 'triple-negative', and it has been proposed that the responsiveness of these patients to therapy may relate to this phenotype. However, in studies the immunohistochemical profiles do not show a significant impact on survival of either 'triple-negative' BRCA carriers or noncarriers within the first 5 years following an initial diagnosis [10]. What is more, in our study the inheritance 
of familial breast cancer does not appear to impact 10-year survival rates. However, our previous study suggested that in BRCA1-positive patients 'triple-negative' was found in $11.7 \%$ of cases, but in familial cancer cases, the prevalence of the corresponding BRCA1 mutation-positive was increased four- to fivefold [11]. Meanwhile, positive family history was again not associated with worse 10-year survival; the adjusted HR was 0.73 (95\% CI: 0.41-1.28; $\mathrm{p}>0.05$ ). In this study only breast cancer of stage II or stage III, independent of mutation status, and age (women older than 52 years), was a strong predictor of mortality; the adjusted HR was (2.78, 95\% CI: 1.46-5.26; 6.02, $3.09-11.75 ; 3.17,1.94-5.19 ; \mathrm{p}<0.05)$ respectively. A recent review shows that among 66 published studies sufficient evidence was only found for a $10 \%$ worse unadjusted recurrence-free survival for BRCA1 mutation carriers. For all the other outcomes, the evidence was judged to be indecisive [12].

The small number of cases in this study may be a limitation for drawing very broad conclusions. Moreover, current evidence in Lithuania does not support worse breast cancer survival of BRCA1 mutation carriers in the adjuvant setting with any possible difference likely to be small. However, it may be concluded that the 10-year survival rates for breast cancer patients with common BRCA1 mutations is similar in both the Polish and Lithuanian population, and are not dependent on their BRCA1 common founder mutation and carrier status.

Financial \& competing interests disclosure

The authors have no relevant affiliations or financial involvement with any organization or entity with a financial interest in or financial conflict with the subject matter or material discussed in the manuscript. This includes employment, consultancies, honoraria, stock ownership or options, expert testimony, grants or patients received or pending, or royalties.

No writing assistance was utilized in the production of this manuscript.

Ethical conduct of research

The authors state that they have obtained appropriate institutional review board approval or have followed the principles outlined in the declaration of Helsinki for all human or animals experimental investigations. In addition, for investigation involving human subjects, informed consent has been obtained from the participants involved.

\section{Open access}

This work is licensed under the Attribution-NonCommercial-NoDerivatives 4.0 Unported License. To view a copy of this license, visit http://creativecommons.org/licenses/by-nc-nd/4.0/

\section{References}

1. Elsakov P, Ostapenko V, Luksyte A, Smailyte G. Management and 5-year survival of BRCA1-associated breast cancer patients. Breast Cancer Manag. 5(3), 119-124 (2016).

2. Huzarski T, Byrski T, Gronwald J et al. Ten-year survival in patients with BRCA1-negative and BRCA1-positive breast cancer. J. Clin. Oncol. 31(29), 3725 (2013).

3. Gorski B, Byrski T, Huzarski T et al. Founder mutation in the BRCA1 gene in Polish families with breast-ovarian cancer Am. J. Hum. Genet. 66, 1963-1968 (2000).

4. Elsakov P, Kurtinaitis J, Petraitis $S$ et al. The contribution of founder mutation in BRCA1 to breast and ovarian cancer in Lithuania. Clin. Genet. 78(4), 373-376 (2010).

5. Tikhomirova L, Sinicka O, Smite D et al. High prevalence of two BRCA1 mutations, 4154delA and 5382insC in Latvia. Fam. Cancer 4 , 77-84 (2005).

6. Oszurek O, Gorski B, Gronvald J et al. Founder mutations in the BRCA1 gene in West Belarusian breast ovarian cancer families. Clin. Genet. 60, 470-471 (2001).

7. Uglianitsa N, Oszurek O, Uglianitsa K et al. The contribution of founder mutation in BRCA1 of breast cancer in Belarus. Clin. Genet. 78, 377-380 (2010).

8. Sokolenko AP, Rozanov ME, Mitiushkina NV et al. Founder mutations in early-onset familial and bilateral breast cancer patients from Russia. Fam. Cancer 6, 281-286 (2007).

9. Goodwin PJ, Phillips K, West D et al. Breast cancer in BRCA1 and BRCA2 mutation carriers: an international prospective breast cancer family registry population-based cohort study. J. Clin. Oncol. 30, 19-26 (2012).

10. Bayraktar S, Gutierrez-Barrera AM, Liu D et al. Outcome of triple-negative breast cancer in patients with or without deletetious BRCA mutation. Breast Cancer Treat. 130(1), 145-153 (2011).

11. Janavicius R, Rudaitis V, Mickys U et al. Comprehensive BRCA1 and BRCA2 mutational profile in Lithuania. Cancer Genet. 207(5), 195-205 (2014).

12. van den Broek AJ, Schmidt MK, van 't Veer LJ, Tollenaar RAEM, van Leeuwen FE. Worse breast cancer prognosis of BRCA1/2 mutation carriers: what's the evidence? A systematic review with meta-analysis. PloS ONE 10(3), e0120189 (2015). 